\section{COTTON CULTIVATION IN THE UNITED STATES OF AMERICA.}

A RECENT event the results of which may be of A far-reaching importance was the visit of the commission appointed by a number of representative cotton-spinners "to make inquiry on the spot so as to ascertain, as nearly as possible, the cost of growing cotton, and the economic conditions under which it is produced in the cotton belt of the United States of America; also to investigate the methods of ginning, baling, marketing, and transport of the product.",

The report of the commissioners is of great interest as affording a critical survey of the methods of cotton cultivation practised in the United States, regarded from the standpoint of the spinner. Moreover, the fundamental problems facing cotton-growers in all parts of the world are essentially similar-to obtain the greatest quantity of good-quality cotton at the lowest cost, to keep in check pests, and to market the product in the best condition.

The lines along, which these problems have been, or are being, solved in the country which at present produces some three-quarters of the world's total commercial cotton crop are of the greatest practical interest in all cotton-producing countries, actual or potential, because the average price at which American cotton can be placed on the market is the ultimate standard of comparison for their own efforts.

It is clear, in the first place, that the United States suffer no restrictions from want of suitable land. Texas alone is estimated to possess sufficient land to produce annually $30,000,000$ bales $^{1}$ of cotton. The average commercial crop of the world is now about I7,000,000 bales, to which the United States contribute Io,600,000, Texas producing about $3,000,000$ bales. Labour conditions in the cotton belt, as well as the recent movement in favour of "diversified farming," are opposed to great extension of the acreage under cotton, and a larger output would appear to depend on increased production per acre.

Seed Selection.- The first place in the practical methods proposed to attain this end is given to seed selection. To those acquainted with the work of Dr. Webber and other officers of the U.S. Department of Agriculture, and the wonderful activity of the department in disseminating agricultural literature and advice, it is somewhat surprising to find that "this is a point to which too little attention has been paid, no doubt owing to lack of knowledge," but, as is pointed out in another connection, the small negro farmer still grows a large portion of the crop, and " it is difficult adequately to describe the slip-shod and primitive methods which he employs." It must be remembered, too, that this report does not deal with "Sea Island",
cotton, and that the careful work on seed selection which has made the cottons from Colonel Rivers's and other estates world famous is not under criticism.

Seed selection conducted on trial plots in an experiment station or in a nursery with a trained staff is tedious and arduous enough, but the practical difficulties are increased a hundredfold on estates with labour of a low order of intelligence. Other practical obstacles are also encountered. The first picking is generally regarded as yielding the best seed, but frequently the farmer has mortgaged his crop and sold in advance both seed and lint of the first and second pickings, and uses seed from the third and worst picking from which to raise the next year's crop. Advances have, however, been made, and two general principles are enun-

1 The weight of a bale of cotton is taken throughout as $500 \mathrm{lb}$. NO. I 940, VOL. 75] ciated. Where labour is abundant the aim should be to select plants maturing over a comparatively long period and giving a large number of pickings. Where labour is scarce the selection should be of plants which ripen all their bolls as nearly as possible at the same time. Two examples are quoted. "Texas Oak" (said to give the greatest yield of upland cotton) gives ro per cent. of the total yield at the first picking and 40 per cent. at each of the second and third pickings. On the other hand, the variety "King " yields 40 per cent. at the first and another 40 per cent. at the second picking: only a fortnight later.

Fertilisers.-In the eastern. States (North and South Carolina, Georgia, and Alabama) of the cotton belt careful attention has been directed to the use of manures, encouraged, it is suggested, by the phosphatic deposits in the neighbourhood of Charleston. Between I879 and 1905 the average yield per acre in these States increased by 35.2 per cent., whilst in the western States the increase during the same period was only 4.2 per cent.

Cultivation.- The negro farmer appears to be largely responsible for the very slow progress effected in this direction. Much land is still cultivated on the "share system," with all its consequent disadvantages. Improvements in cultural implements have been very rare, and the great desideratum is still an efficient cotton-picking machine; this operation alone costing now about $2 \frac{1}{4}$ cents per $1 \mathrm{~b}$. of lint-practically a quarter of the total cost of production.

PESTs.-The cotton boll weevil (Anthonomus grandis) is the most serious of all the American cotton pests. It now infests about one-third of the cotton area, is advancing at the rate of fifty miles per annum, and reduces the crop to about one-half in attacked areas. The loss due to it in Texas alone in 1904 was estimated at 22,000,000 dollars. Clean cultivation, the burning of old plants, and the establishment of early maturing and resistant varieties by seed selection work appear the most promising methods for dealing with this formidable pest.

GINNING.-The saw-gin, first invented by Whitney more than a century ago, still holds the field by virtue of its large output, although its defects are well recognised. Interesting information is afforded on other types of gins, still more or less in the experimental stage.

Baling.-The bad qualities of the American cotton bale are notorious, and the commissioners quote as "none too severe"' Judge Ogden's description of it at the Washington Conference of Spinners and Planters in May last as " a dirty, damaged, disreputable, watersoaked, wasteful, slovenly, clumsy, highly inflammable, turtle-backed package."

The American bale has a density of only $22 \mathrm{lb}$. per cubic foot, as opposed to $37 \mathrm{lb}$. and $56 \mathrm{lb}$. for Egyptian and Indian bales respectively. A bale with a density of about $40 \mathrm{lb}$. per cubic foot is recommended, and other improvements advocated in regard to packing, \&c., which, if carried out, would, it is estimated, result in a saving of about $1,000,000 l$. annually, chiefly in cost of freight.

The principal recommendations and criticisms contained in the report are worthy of serious consideration in all countries engaged in the cultivation of cotton. An effort may soon be made to put them into practice in the United States, as, owing to the action of the cotton growers' associations in attempting to control supplies, a proposal is under consideration for English spinners to establish plantations in the cotton belt, and a second commission has already left England to select a suitable scene of operations. 